\title{
Caffeine Accelerates Cystic Kidney Disease in a Pkd1-Deficient Mouse Model
}

\author{
Renata Meca ${ }^{a}$ Bruno E. Balbo ${ }^{b}$ Milene Subtil Ormanjia Jonathan M. Fonsecab \\ Leandro R. Iannuzzi ${ }^{b}$ Eliene Santana Costa ${ }^{b}$ Luiz F. Onuchic ${ }^{b}$ \\ Ita Pfeferman Heilberga
}

aNephrology Division, Universidade Federal de São Paulo, São Paulo, Brazil, 'Nephrology Division, Universidade de São Paulo, São Paulo, Brazil

\section{Key Words}

ADPKD • Pkd1 gene $\cdot$ Caffeine $\cdot$ Cystic kidney disease progression $\cdot$ Cell proliferation $•$ Kidney fibrosis

\begin{abstract}
Background/Aims: Autosomal dominant polycystic kidney disease (ADPKD) is characterized by progressive cyst formation and growth, leading to end-stage renal disease. A higher kidney volume is predictive of a more accelerated decline in renal function. This study aimed to examine the effects of caffeine, a phosphodiesterase inhibitor, on the progression of cystic kidney disease in a mouse model orthologous to human disease (Pkd1 ${ }^{\text {cond/cond:Nestin }}{ }^{\text {cre) }}$. Methods: Caffeine was administered to male cystic (CyCaf) and noncystic (NCCaf) mice (Pkd1 1 cond/cond) from conception and at the postweaning period through 12 weeks of life (3 $\mathrm{mg} / \mathrm{d}$ ), while control animals consumed water (CyCtrl and NCCtrl). Renal ultrasonography was performed at 10 weeks of life to calculate total kidney volume and cystic index. At the end of the protocol, blood and urine samples were collected for biochemical analysis, and animals were euthanized. Kidneys were harvested to obtain renal tissue for determinations of adenosine 3'5'-cyclic monophosphate (cAMP) by an enzymatic immunoassay kit and phosphorylated extracellular signal-regulated kinase ( $p$-ERK) by Western blotting. Renal fibrosis (picrosirius staining), renal cell proliferation (ki-67 immunohistochemistry) and apoptotic rates (TUNEL analysis) were also determined. Results: At 12 weeks, CyCaf mice exhibited higher serum urea nitrogen, renal cystic index, total kidney volume, kidney cell proliferation, apoptosis and fibrosis compared with CyCtrl mice. Serum cystatin $\mathrm{C}$ was significantly higher in CyCaf than in NCCaf and NCCtrl mice. CyCaf mice had higher total kidney weight than all other groups but not higher heart and liver weight. The levels of CAMP and $p$-ERK did not differ among the groups. Conclusion: Caffeine consumption from conception through 12 weeks led to increased cystic index and total kidney volume and worsened renal function in Pkd1deficient cystic mice, suggesting that high consumption of caffeine may contribute to a faster progression of renal disease in ADPKD.

I.P. Heilberg and L.F. Onuchic contributed equally to this work. 


\section{Cellular Physiology Cell Physiol Biochem 2019;52:1061-1074 \\ \begin{tabular}{ll|l} 
and Biochemistry & $\begin{array}{l}\text { DOl: 10.33594/000000072 } \\
\text { Published online: } 13 \text { April 2019 }\end{array}$ & $\begin{array}{l}\text { O } 2019 \text { The Author(s). Published by } \\
\text { Cell Physiol Biochem Press GmbH\&Co. KG }\end{array}$ \\
\cline { 2 - 3 } &
\end{tabular} \\ Meca et al.: Caffeine and Cystic Kidney Disease in Mice}

\section{Introduction}

Autosomal dominant polycystic kidney disease (ADPKD), the most frequent monogenic renal disease, is characterized by the development and growth of multiple renal cysts and progressive kidney fibrosis, ultimately leading to loss of renal function [1, 2]. ADPKD is caused by mutations in PKD1 or PKD2, genes that encode polycystin-1 and polycystin-2, respectively. These proteins modulate a number of molecular pathways, regulating several aspects of tissue morphogenesis and function. Disruption of polycystin function leads to an abnormal proliferative response of ADPKD cyst cells to the second messenger cAMP (3'5'-cyclic monophosphate) in response to decreased cytosolic $\mathrm{Ca}^{+2}$, favoring intracellular cAMP accumulation, stimulating cell proliferation and transepithelial fluid secretion [3-5]. The precise underlying mechanisms that modulate cyst formation and ADPKD progression, however, have not been fully elucidated.

Predicting factors associated with early adverse structural and/or functional outcomes include the affected locus, the type of PKD1 mutation, male gender, early onset of hypertension, gross hematuria and increase in kidney volume [6]. In recent years, numerous pieces of evidence have supported a surrogate marker role for the rate of increase in total kidney volume (TKV) with respect to the progressive decline in glomerular filtration rate (GFR) [7-9]. These data led to the development of prognostic prediction tools for renal function decline, specifically the classification proposed by Irazabal et al. [9] based on age and TKV corrected for height. Given the natural history of ADPKD, the identification of potentially modifying factors that may influence the course of renal disease is essential to preclude avoidable acceleration or to attenuate its course, particularly in fast progressors [10]. Increased water intake, reduction in protein and sodium consumption, and caffeine restriction represent some of the proposed dietary approaches [10-13]. Interestingly, caffeine has been shown to increase p-ERK levels, a key intermediate for cell proliferation, in cultured epithelial cells from ADPKD cysts, suggesting that this methylxanthine may contribute to cyst enlargement. Chronic caffeine exposure, in turn, was shown to exacerbate hypertension but had no effect on cyst development in a nonorthologous model of PKD [14]. In the current study, we investigated the in vivo effects of chronic caffeine consumption on the progression of ADPKD renal disease by submitting Pkd1-deficient cystic mice (Pkd1 ${ }^{\text {cond/ }}$ cond: Nestin ${ }^{\text {cre }}$ ), a model orthologous to human ADPKD, to high caffeine intake from conception to 12 weeks of life.

\section{Materials and Methods}

\section{Animal model}

The cystic mice used in this study were homozygous for a Pkd1-floxed allele and displayed a mosaic profile of gene inactivation induced by a Nestin-Cre transgene, leading to excision of exons 2-4 (Pkd1 ${ }^{\text {cond/cond }}$ :Nesti $\left.{ }^{\text {cre }}\right)$.

$P k d 1$-deficient male mice $\left(P k d 1^{\text {cond/cond:Nestin }}{ }^{\text {cre }}\right)$ were bred with noncystic females ( $\left.P k 1^{\text {cond/cond }}\right)$ submitted to caffeine (added to drinking water), reaching a consumption of approximately $3 \mathrm{mg} / \mathrm{d}$. Caffeine administration was initiated 2 weeks prior to breeding, persisted during pregnancy and ended 5 weeks after the birth of the pups. Only male animals were selected from the offspring, including cystic and noncystic mice. These animals were genotyped using specific PCRs. All of them started caffeine consumption at $3 \mathrm{mg} / \mathrm{d}$ soon after weaning, which was terminated at 12 weeks of life. The CyCaf and NCCaf groups included 10 animals each. To obtain a cystic and noncystic control group, similar breedings given plain water instead of caffeine were established, giving rise to 10 cystic male mice of the same strain that were provided plain drinking water for a similar period of life (CyCtrl and NCCtrl groups). 


\section{Cellular Physiology Cell Physiol Biochem 2019;52:1061-1074 \\ \begin{tabular}{ll|l} 
and Biochemistry & $\begin{array}{l}\text { DOl: 10.33594/000000072 } \\
\text { Published online: } 13 \text { April 2019 }\end{array}$ & $\begin{array}{l}\text { O } 2019 \text { The Author(s). Published by } \\
\text { Cell Physiol Biochem Press GmbH\&Co. KG }\end{array}$ \\
\cline { 2 - 3 } &
\end{tabular} \\ Meca et al.: Caffeine and Cystic Kidney Disease in Mice}

All animals were euthanized at 12 weeks with intraperitoneal sodium pentobarbital, and their kidneys, liver and heart were weighed and normalized to their BW. The kidneys were appropriately harvested for further biochemical, immunohistochemical and staining analyses.

\section{Renal ultrasonographic assessment}

Renal ultrasonographic evaluation was performed at 10 weeks of age in CyCaf and CyCtrl animals using a Vevo $2100 \AA$ device (Visual Sonics ${ }^{\circledR}$ Inc, Toronto, Canada) with a 40$\mathrm{mHz}$ transducer. This procedure was conducted under isoflurane inhalation anesthesia. Bidimensional images were acquired for both kidneys, allowing three-axis measurements thereafter used to quantify kidney volume by applying the modified ellipsoid volume equation [15]. The measurement of individual cyst volume was supported by a 200-image scan acquired in axial cut within 3-s periods. Calculation of this volume was based on cyst diameter, assuming a spherical cyst configuration. The renal cystic index was then calculated as the ratio between the sum of all cyst volumes of both kidneys and the total volume of these organs.

\section{Analyses of biochemical parameters}

Blood samples were drawn by retro-orbital bleeding for determination of BUN using colorimetric assays (Labtest, Lagoa Santa, Brazil) and serum cystatin C levels, measured using an ELISA (Enzyme Linked Immuno-Sorbent Assay) kit (Sigma-Aldrich, St Louis, USA). Renal concentrating capacity was analyzed by determining $U_{\text {osm }}$ Max. The animals were kept in metabolic cage for $32 \mathrm{~h}$ with food but no water. This period was followed by a subcutaneous injection of desmopressin (DDAVP) at $1.0 \mu \mathrm{g} / \mathrm{kg} \mathrm{BW}$ and return to the metabolic cage. After a subsequent period of $10 \mathrm{~h}$, the animals were weighed, and urine was collected for osmolality determination using a Vapro 5500 vapor osmometer (Wescor, Logan, USA). Part of the available renal tissue was homogenized in $0.1 \mathrm{M} \mathrm{HCl}$ for cAMP quantification. Such levels were measured in the corresponding lysates using an enzymatic immunoassay kit (SigmaAldrich, St Louis, USA). For both cAMP and renal concentration capacity parameters, some values (CyCtrl group) were taken from previously reported data by our group (Fonseca et al., 2014) [16] and added to ours.

\section{Immunohistochemical analyses}

Kidney tissuewasfixed, paraffin embedded, slicedand prepared for immunohistochemical analyses. Quantification of cell proliferation was based on Ki-67 staining using a monoclonal antibody (Abcam, Cambridge, USA), while the TUNEL technique (terminal deoxynucleotidyl transferase dUTP nick end labeling) was used to determine the apoptotic rates (Roche, Mannheim, Germany). Both quantifications were performed under light microscopy (400x magnification), and the results were expressed as ratios of positive cells/total cells. Ten kidney fields (eight positioned in the renal cortex and two located in the renal medulla) were analyzed for each animal.

\section{Western blotting}

Kidney proteins were extracted with RIPA buffer and quantified using the modified Lowry method (Bio-Rad laboratories, USA). Then, $50 \mu \mathrm{g}$ protein samples were separated by $10 \%$ SDS-PAGE electrophoresis and transferred to nitrocellulose membranes (GE Life Sciences, United Kingdom). The membrane blots were incubated with primary ERK and phospho-ERK antibodies (1:1000, Cell Signaling Technology) overnight at $4^{\circ} \mathrm{C}$ and with goat anti-rabbit HRP-conjugated secondary antibodies (GE Life Sciences) for $1 \mathrm{~h}$ at $4^{\circ} \mathrm{C}$. Protein bands were visualized using the Immobilon Western HRP substrate (Millipore) and quantified using Uvitec analyses software (Uvitec Limited, Cambridge, United Kingdom). The phospho-ERK/ERK ratio was calculated, and the values are represented as p-ERK/ERK (\%). 


\section{Renal fibrosis quantification}

Kidney sections were stained with picrosirius red (Direct Red 80, Milwaukee, EUA) and analyzed using an optical microscope (400x magnification). Defined images were then processed using software (LAS V3.8 Ink, Leica Microsystems Framework, Switzerland), allowing fibrosis quantification by selection of red collagen areas. The fibrosis index was expressed as the ratio between the collagen content and total field areas.

\section{Statistical analyses}

All data are reported as the mean \pm SD or median [interquartile range].

Comparison between two groups was performed using the unpaired $t$ test or MannWhitney, according to the distribution of each variable. For comparisons of more than two groups, data were compared by ANOVA with Bonferroni post hoc test or Kruskal-Wallis with Mueller-Dunn post hoc test.

The tests were applied using SigmaStat 3.5 (Systat $\AA$ Software) and GraphPad 5.0 (Prism® Software). A significance level of 0.05 and a confidence level of $95 \%$ were considered appropriate.

\section{Results}

Caffeine is associated with low body weight (BW) in cystic and noncystic mice

Although all groups obtained significantly higher BW at 12 weeks compared to that at weaning, caffeine consumption resulted in a lower BW in cystic and noncystic mice at both evaluated ages (Table 1).

Cystic mice subjected to high caffeine consumption develop larger kidneys

Total kidney weight normalized to BW (TKW/BW) was significantly higher in CyCaf mice than in CyCtrl, NCCaf and NCCtrl mice (Table 1). However, kidney weight did not differ statistically between CyCtrl and NCCtrl mice. No significant differences in heart and liver weight were detected among all groups.

Cystic mice subjected to high caffeine consumption exhibit reduced renal function and renal concentration capacity but not increased renal cAMP or $p$-ERK

CyCaf mice presented higher serum urea nitrogen than CyCtrl and NCCtrl animals at 12 weeks ( $38.0 \pm 10.8$ versus $20.7 \pm 5.6, p<0.001$, and $21.4 \pm 3.2 \mathrm{mg} / \mathrm{dL}, \mathrm{p}<0.01)$ (Fig. 1$)$. CyCaf mice developed higher serum cystatin C levels than NCCaf and NCCtrl animals $(4.34 \pm 1.1$ versus $2.52 \pm 0.42$ and $1.72 \pm 0.12 \mathrm{pg} / \mathrm{mL} ; \mathrm{p}<0.001$, respectively). CyCtrl mice also displayed more elevated serum cystatin $C$ values than NCCaf and NCCtrl mice (3.81 \pm 0.82 versus $2.52 \pm 0.42$, $\mathrm{p}<0.05$, and $1.72 \pm 0.12 \mathrm{pg} / \mathrm{ml}, \mathrm{p}<0.01$, respectively).

Table 1. Comparison of body weight (BW), heart weight (HW), liver weight (LW) and total kidney weight (TKW)Comparison intergroups: ${ }^{a} \mathrm{p}<0.05$ and ${ }^{\mathrm{b}} \mathrm{p}<0.001$ versus CyCtrl; ${ }^{\mathrm{c}} \mathrm{p}<0.001$ versus NCCaf; ${ }^{\mathrm{d}} \mathrm{p}<0.05$ and ${ }^{\mathrm{e}} \mathrm{p}<0.001$ versus NCCtrl, and intragroups: ${ }_{\mathrm{f}}^{\mathrm{f}}<0.001$. Cystic animals: caffeine (CyCaf), control (CyCtrl); noncystic animals: caffeine (NCCaf) and control (NCCtrl)

\begin{tabular}{|c|c|c|c|c|c|}
\hline \multirow[t]{2}{*}{ Parameters } & \multicolumn{2}{|c|}{ BW(g) } & \multirow[t]{2}{*}{ HW/BW (\%) } & \multirow{2}{*}{$\begin{array}{r}\text { LW/BW (\%) } \\
12 \text { weeks }\end{array}$} & \multirow[t]{2}{*}{ TKW/BW (\%) } \\
\hline & Weaning & 12 weeks & & & \\
\hline CyCaf & $\begin{array}{c}12.1 \pm 2.5^{\mathrm{b} \text { e }} \\
(\mathrm{n}=10)\end{array}$ & $\begin{array}{c}16.5 \pm 3.2^{\mathrm{b} \text { e } \mathrm{f}} \\
(\mathrm{n}=10)\end{array}$ & $\begin{array}{c}0.55 \pm 0.08 \\
(\mathrm{n}=10)\end{array}$ & $\begin{array}{l}5.2 \pm 0.7 \\
(\mathrm{n}=10)\end{array}$ & $\begin{array}{c}2.4[1.8-3.5] \text { bce } \\
(n=10)\end{array}$ \\
\hline CyCtrl & $\begin{array}{c}19.5 \pm 1.3^{c} \\
(n=10)\end{array}$ & $\begin{array}{c}24.7 \pm 2.0^{\mathrm{ef}} \\
(\mathrm{n}=10)\end{array}$ & $\begin{array}{c}0.54 \pm 0.04 \\
(n=8)\end{array}$ & $\begin{array}{c}4.7 \pm 0.3 \\
(n=8)\end{array}$ & $\begin{array}{c}1.4[1.3-1.8] \\
(n=8)\end{array}$ \\
\hline NCCaf & $\begin{array}{c}13.6 \pm 1.7 \mathrm{~d} \\
(\mathrm{n}=10)\end{array}$ & $\begin{array}{c}17.9 \pm 2.9 \text { e f } \\
(n=10)\end{array}$ & $\begin{array}{c}0.52 \pm 0.04 \\
(n=10)\end{array}$ & $\begin{array}{l}4.6 \pm 0.5 \\
(n=10)\end{array}$ & $\begin{array}{c}1.5[1.4-1.7] \\
(n=10)\end{array}$ \\
\hline NCCtrl & $\begin{array}{c}19.2 \pm 0.9 \\
(n=5)\end{array}$ & $\begin{array}{c}26.8 \pm 2.5^{f} \\
(n=5)\end{array}$ & $\begin{array}{c}0.52 \pm 0.04 \\
(n=5)\end{array}$ & $\begin{array}{c}5.1 \pm 0.3 \\
(n=5)\end{array}$ & $\begin{array}{c}1.3[1.2-1.6] \\
(n=8)\end{array}$ \\
\hline
\end{tabular}


Fig. 1. Comparative analyses of parameters of renal function: BUN, blood urea nitrogen (a), NCCtrl $n=5$, NCCaf $n=10$, CyCtrl n=7, CyCaf $n=10$, and cystatin $C(b)$, NCCtrl $n=5$, NCCaf $n=8$, CyCtrl $n=6$, CyCaf $\mathrm{n}=9$. Caffeine: cystic (CyCaf) and noncystic (NCCaf) and controls: cystic (CyCtrl) and noncystic (NCCtrl).* $\mathrm{p}<0.05$; ${ }^{* *} \mathrm{p}<0.01,{ }^{* * *} \mathrm{p}<0.001$.

Fig. 2. Comparative analyses of renal cAMP levels (a), NCCtrl $n=7$, NCCaf $n=5$, CyCtrl $n=5$, CyCaf $n=4$; renal p-ERK/ERK levels (b), NCCtrl $n=5$, NCCaf $n=5$, CyCtrl n=5, CyCaf $n=4$ and renal concentration capacity (maximum urine osmolality, UosmMax) (c), NCCtrl $\mathrm{n}=9$, NCCaf $n=8$, CyCtrl $n=6$, CyCaf $n=6$, among groups at $10-12$ weeks. Caffeine: cystic (CyCaf) and noncystic (NCCaf) and controls: cystic (CyCtrl) and noncystic (NCCtrl). ${ }^{*} \mathrm{p}<0.05$, $* * \mathrm{p}<0.001$.
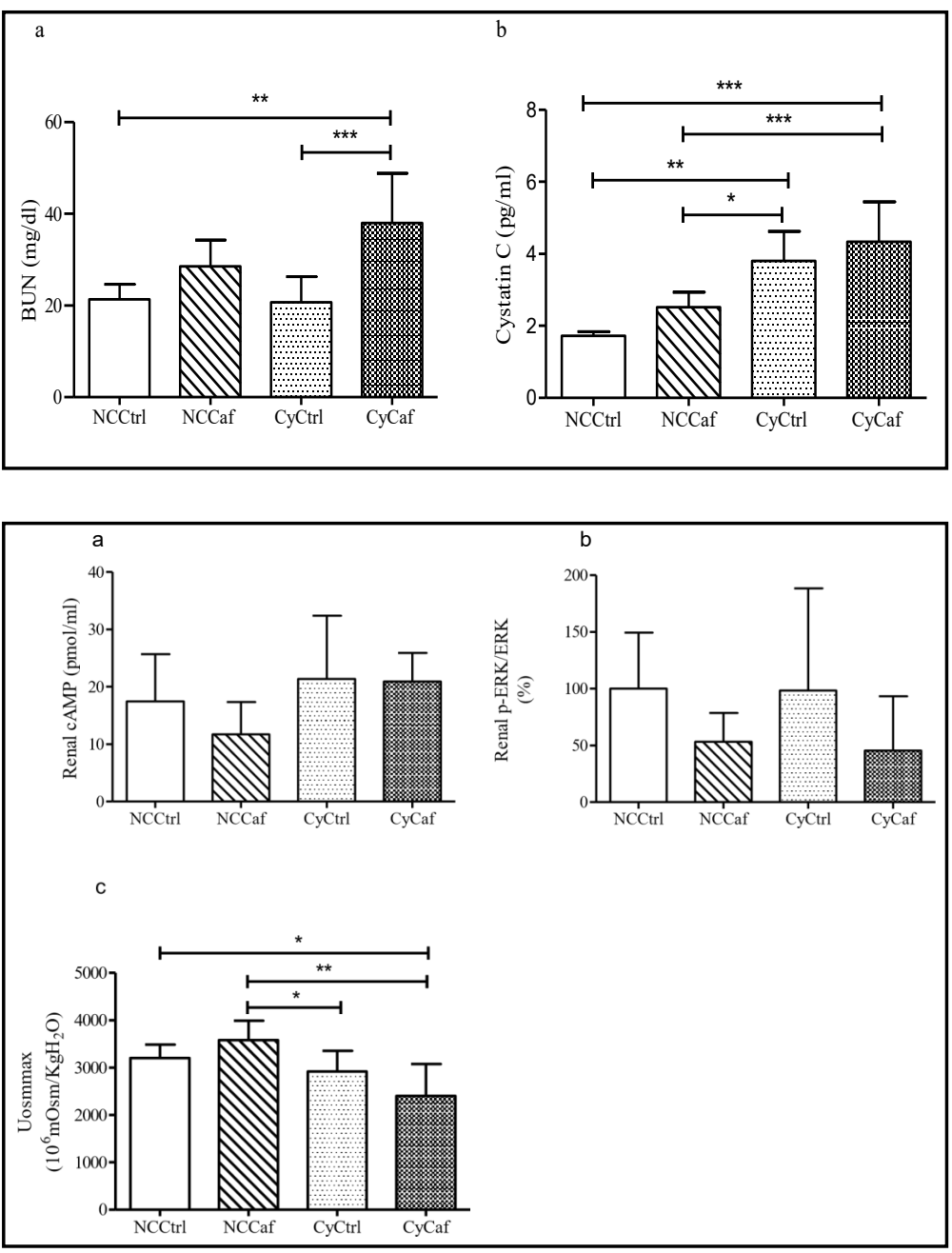

The renal concentration capacity was also affected by caffeine in cystic mice. Maximum urine osmolality ( $\mathrm{U}_{\text {osm }}$ Max) was significantly lower in CyCaf mice compared with that in NCCaf and NCCtrl mice (2396 \pm 677 versus $3577 \pm 411, \mathrm{p}<0.001$ and $3199 \pm 288 \mathrm{mOsm} / \mathrm{kg} \mathrm{H}_{2} \mathrm{O}$, $\mathrm{p}<0.05$, respectively) (Fig. 2). Although unexpected, renal cAMP levels did not significantly differ among groups. (Fig. 2). The renal levels of p-ERK/ERK were also not significantly different among the groups. (Fig. 2).

High caffeine consumption increases cyst growth and kidney volume in cystic mice

Ultrasonographic analyses showed cysts with increased size in caffeine-consuming cystic mice compared to those in control cystic animals (Fig. 3). Our images also suggest a higher number of detectable cysts in CyCaf kidneys than in CyCtrl kidneys. In line with such observations, ultrasonographic image analyses performed at 10 weeks revealed significantly higher TKV in CyCaf animals than in CyCtrl animals $\left(27.9 \pm 10.9\right.$ versus $16.7 \pm 4.6 \mathrm{~mm}^{3} / \mathrm{g} \mathrm{BW}$, $\mathrm{p}<0.001)$ as well as a higher kidney cystic index $(38.73 \pm 15.68$ versus $9.44 \pm 8.73 \%$; $<<0.001$ ) (Fig. 3).

Caffeine increases cell proliferation, apoptosis and fibrosis in cystic kidneys

Cell proliferation rates were significantly higher in CyCaf kidneys than in CyCtrl, NCCaf and NCCtrl kidneys at 12 weeks $(5.08 \pm 1.82$ versus $2.35 \pm 0.88,0.57 \pm 0.29, \mathrm{p}<0.01$ and $1.29 \pm 0.20 \%, \mathrm{p}<0.001$, respectively) (Fig. 4). These data indicate increased susceptibility of CyCaf renal cells to caffeine-induced proliferation. 


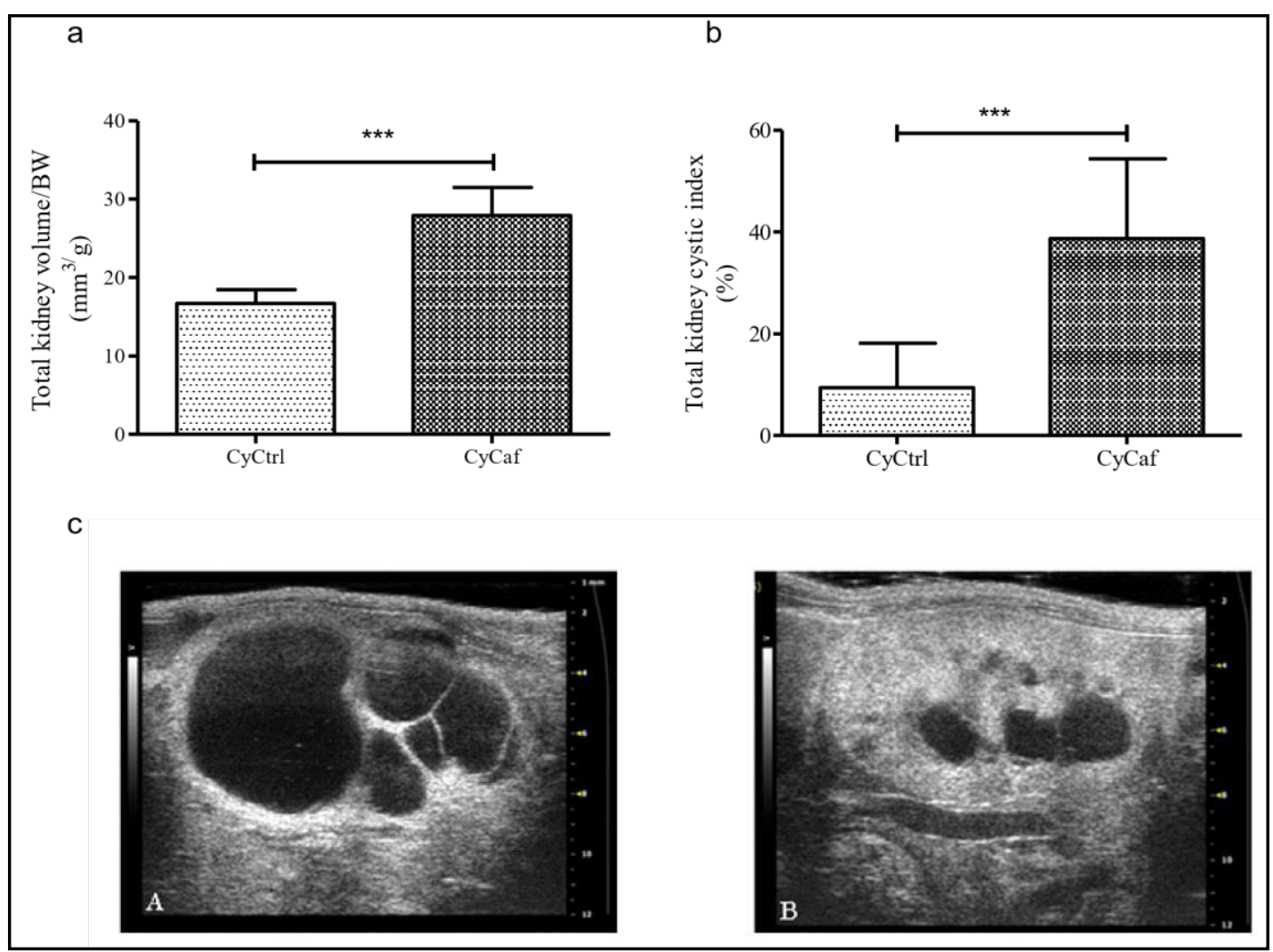

Fig. 3. Comparative analyses, at 10 weeks, of total kidney volume corrected for body weight, TKV/BW (a)CyCaf $n=9$, CyCtrl $n=7$ and total kidney cystic index (b) CyCaf n=9, CyCtrl n= 7. ${ }^{* *} \mathrm{p}<0.001$. Kidney ultrasonographic images (c) of cystic animals consuming (A) caffeine or (B) water. Cystic caffeine (CyCaf) and control (CyCtrl).

Fig. 4. Comparative analyses of the cell proliferation index (a) and apoptosis (b) among the NCCtrl (n=5), NCCaf $(n=5)$, CyCtrl $(n=5)$ and CyCaf $(n=6)$ groups. Caffeine: cystic (CyCaf) and noncystic (NCCaf) and controls: cystic (CyCtrl) and

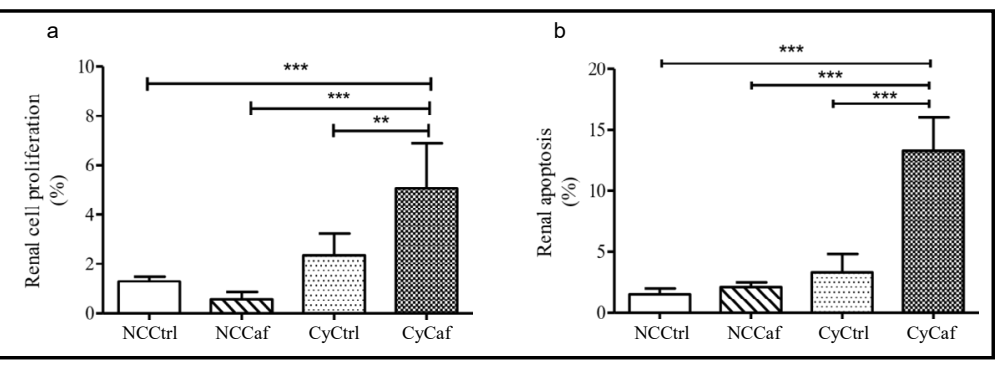
noncystic (NCCtrl). ${ }^{* *} \mathrm{p}<0.01$, $* * * \mathrm{p}<0.001$.

A similar effect was observed with respect to apoptosis. TUNEL analyses revealed higher apoptotic rates in CyCaf kidneys than in CyCtrl, NCCaf and NCCtrl kidneys $(13.29 \pm 2.77$ versus $3.31 \pm 1.51,2.10 \pm 0.36$ and $1.51 \pm 0.46 \%$; p <0.001) (Fig. 4).

CyCaf kidneys also displayed an increased fibrosis index compared to CyCtrl, NCCaf and NCCtrl kidneys (19.64 \pm 6.48 versus $8.1 \pm 1.50,3.12 \pm 1.25$ and $4.70 \pm 0.74 \%$, $p<0.001$ ) (Fig. 5). 


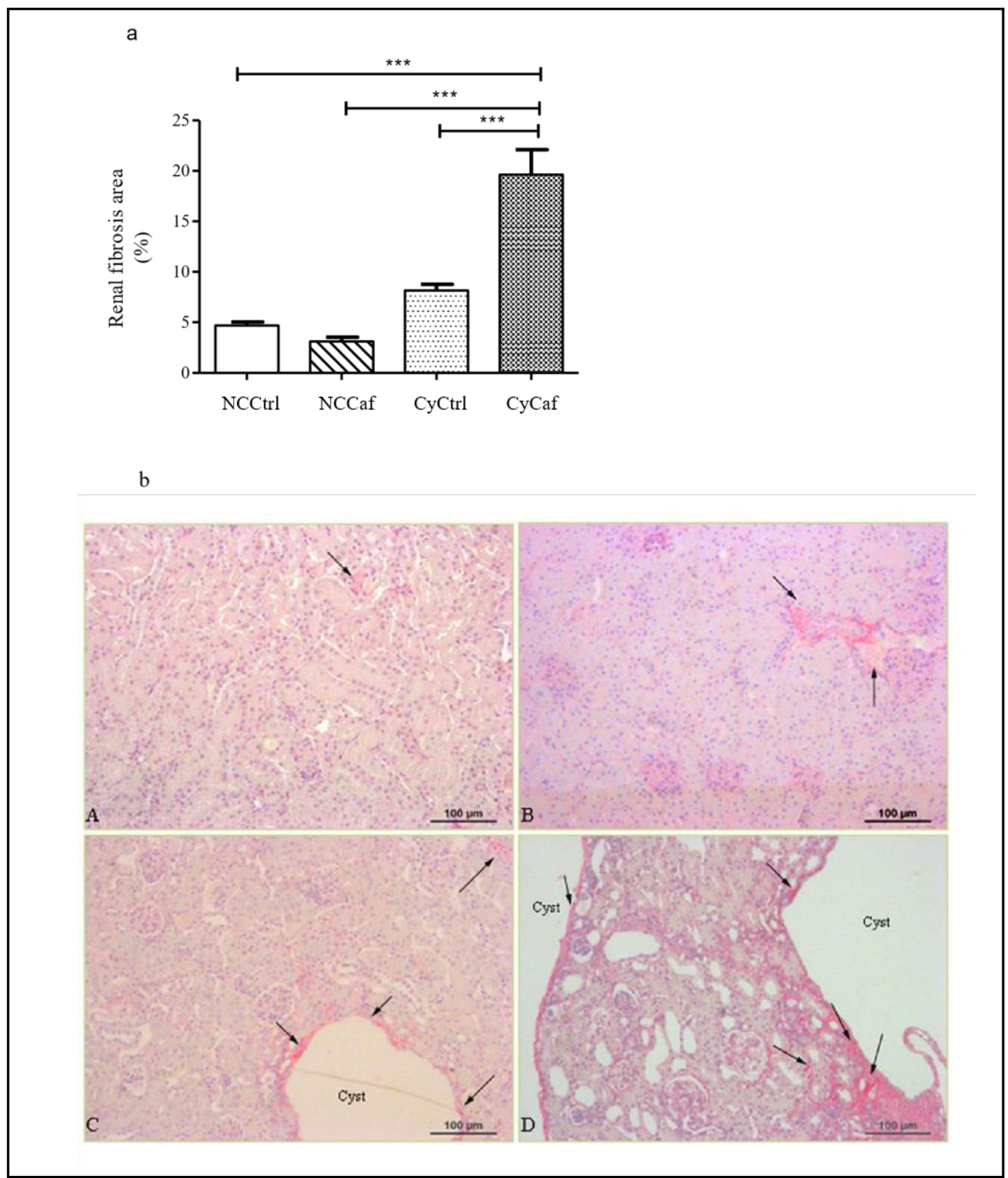

Fig. 5. Comparative analyses of areas of renal fibrosis (a) among the NCCtrl (n=5), NCCaf ( $n=9), \operatorname{CyCtrl}(n=6)$ and CyCaf (n=7) groups and representative images of Picrossirius red staining (b) in the NCCtrl(A), NCCaf (B), CyCtrl (C) and CyCaf (D) groups (original magnification x400). Cystic: caffeine (CyCaf) and noncystic (NCCaf) and controls: cystic (CyCtrl) and noncystic (NCCtrl); ${ }^{* * *} \mathrm{p}<0.001$. Arrows indicate areas of fibrosis.

\section{Discussion}

ADPKD patients undergo decades of a progressive increase in kidney size associated with relatively preserved renal function before the initiation of a significant deterioration in GFR $[1,2]$. Higher rates of TKV increase, however, are predictive of a more accelerated decline in renal function long-term [6]. The role of cAMP in promoting cyst growth has been supported by a number of studies $[4,17,18]$. Since the arginine vasopressin (AVP)-V2 receptor (AVPR2) system has been recognized as the main cAMP generator in principal cells, the effects of AVPR2 antagonists have been analyzed in different animal models of PKD. 
Interestingly, such agents inhibited or diminished progression of the renal cystic phenotype in models orthologous to human ADPKD [19-21]. As a natural follow up, the recent TEMPO $3: 4$ study revealed that tolvaptan decreased the annual rates of TKV increase and GFR decline [22].

Based on this concept, a previous study was designed to interfere with cAMP generation mediated by the AVP-AVPR2 axis by substantially increasing water intake. The expected decrease in serum AVP levels, in fact, was accompanied by cyst growth attenuation in the PCK rat [23]. In this context, ADPKD patients have been advised to increase water intake. As an extension of this strategy, Belibi et al. [18] considered the fact that caffeine might play a significant role in increasing cAMP cell levels because it inhibits phosphodiesterase. These investigators found that caffeine slightly increased basal levels of cAMP in ADPKD cells and, in clinically relevant concentrations, potentiated the effects of DDAVP upon the cAMP increase in both ADPKD and normal human kidney cortex cells [18]. Since then, caffeine consumption has been assumed to represent a potential environmental risk factor for ADPKD acceleration $[6,18]$.

However, only one small cross-sectional clinical study, conducted by Vendramini et al. [13], has thus far evaluated caffeine intake by ADPKD patients and revealed lower consumption in this population compared to that in healthy volunteers, probably due to prior awareness of the need for caffeine restriction. Within the observed range of caffeine intake, renal volume was not significantly associated with it [13]. Another recent longitudinal clinical study [24] did not find a correlation between coffee consumption and kidney size and disclosed no association with disease progression in a cohort of ADPKD patients. Nevertheless, limitations that could have led to underestimation of the long-term effects of caffeine included the low number of follow-up visits and the self-reported determination of coffee consumption excluding cola, energy drinks and black tea, as reported by the authors [24]. Notwithstanding the controversy and scarce support of the recommendation of caffeine restriction to ADPKD patients, no in vivo study addressing the potential influence of caffeine on disease progression has yet been performed in an animal model orthologous to human ADPKD. This analysis is perceived as fundamental, given the severe limitations of addressing this theme in a human study. To perform such an assessment in an appropriate way, we chose an animal model orthologous to ADPKD and with a relatively mild cystic phenotype, features that would allow more translational and likely more sensitive detection of the potential deleterious effects of caffeine on cystic kidneys. In the present study, administration of caffeine from conception to 12 weeks of life led to a higher cystic index and increased kidney volume in Pkd1-deficient cystic mice, as well as to increased cell proliferation and fibrosis.

A lower BW was observed in cystic and noncystic animals submitted to caffeine intake than in controls, both at 5 and 12 weeks of age. This finding suggests that this deleterious effect of caffeine, at the analyzed dose, was not specific to the Pkd1 deficiency status. Our data are in agreement with previous studies that reported an association of maternal caffeine exposure during pregnancy with low birth weight [25, 26]. Nonetheless, no difference in percent weight gain was detected among all mouse groups (data not shown), dismissing potential harm to comparisons involving other parameters. Notably, total kidney weight normalized to BW was significantly higher in CyCaf mice than in all other groups. The absence of total kidney weight difference between CyCtrl and NCCtrl mice, although a priori unexpected, may have occurred due to the wide variability of renal cystic burden observed in our model [16]. Such a variation is likely based on the mosaic and nonsynchronous expression of Nestin-Cre [27].

Renal cystic index and kidney volume were markedly increased in cystic animals receiving caffeine compared to those in their cystic controls, bringing up for the first time the proof of principle that caffeine can lead to cyst enlargement in an in vivo model orthologous to human ADPKD. This finding is of utmost importance, given that TKV is currently the most employed surrogate marker for the progression of GFR decline in ADPKD $[10,28,29]$. The wide caffeine consumption by the general population, moreover, places it as a major potentially modifiable factor for ADPKD progression [6]. Since caffeine inhibits 
phosphodiesterase (PDE) and renal cAMP has been shown to be increased in PKD murine models [30], CyCaf kidneys were expected to present higher cAMP levels than CyCtrl and NCCaf kidneys. While we have no clear explanation for not having found this result, the remarkably higher cystic index observed in CyCaf kidneys may have limited the number of cAMP-producing cells per kidney volume, reducing the absolute value and, therefore, underestimating cAMP generation in CyCaf kidneys. It is important to note, however, that Ye et al. [31] have recently reported that knocking out Pde1a, Pde1c and Pde3a aggravated the cystic phenotype in Pkd2(-/WS25) mice without significantly affecting renal cAMP content. Such findings suggest that distinct subcellular expression patterns of different PDEs are important for the functional compartmentalization of cAMP-mediated responses and raise the concern that cAMP measurements in whole-tissue lysates may be associated with inadequate sensitivity and specificity. Notably, caffeine can stimulate $\mathrm{Cl}^{-}$transport directly, independent of cAMP [32], an effect that could potentially contribute to $\mathrm{Cl}^{-}$-mediated transepithelial fluid secretion and consequent cyst growth. The same unexpected findings were observed for the lack of difference regarding ERK activation in caffeine versus control groups and a slight nonsignificant reduction in its levels instead. Consistent with the present data, Miwa et al. (2012) observed suppressed ERK activation in response to exposure of osteosarcoma cells to caffeine [33]. Furthermore, as further shown by Wang et al. [34], the addition of caffeine to hepatic stellate cells disclosed an inhibitory effect upon phosphorylation of ERK1/2 and led to a significant decrease in cAMP/PKA signaling.

Finally, caffeine might lead to renal hemodynamic changes in certain phases of life, which might reduce kidney perfusion and establish sectorial areas of renal ischemia. In this scenario, caffeine may induce third hits, following a process proposed by other investigators [35-37], thereby contributing to cyst formation and disease progression by an additional mechanism.

In line with previous studies [38-40], CyCaf animals had significantly higher BUN than CyCtrl and NCCtrl animals. Although CyCaf mice presented higher serum cystatin C than NCCaf and NCCtrl mice, no significant difference was observed between the two cystic groups. The lack of BUN difference between cystic and noncystic animals is in contrast to previous experiments in mice at 13 weeks of life [16]. However, although significant in the referred study, the increase in BUN in cystic mice compared to that in noncystic animals was very small. The discrepancy between our and such data, therefore, is again likely explained by the variability in the cystic phenotype displayed by our mouse model. The current findings show that caffeine per se did not impair GFR in noncystic mice and suggest a lack of significant additional loss of renal function induced by caffeine in cystic animals. Caffeine intake reduced renal concentrating capacity in cystic mice, but such an isolated effect of caffeine could not be attributed to an expected AVP inhibition [41-43] since $U_{\text {osm }}$ Max was not reduced in NCCaf animals. Altogether, caffeine likely exerts its reducing effect on renal concentrating capacity primarily by enhancing cyst growth in $P k d 1$-deficient cystic mice, in line with the concept that the severe structural disruption of renal architecture is the main determinant for the renal concentrating deficit associated with ADPKD [44, 45].

The cell proliferation and apoptosis rates were higher in CyCaf kidneys than in the kidneys of all other groups. Interestingly, although CyCtrl exhibited numerically higher rates than NCCtrl mice, no significant difference in renal cell proliferation and apoptosis was detected, in contrast to a previous study performed with the same model [16] and in other cystic animal models, which showed increased proliferation and apoptosis in cyst-lining cells [46-48]. Of note, caffeine may lead to minor pro-proliferative and pro-apoptotic effects on noncystic kidney cells, neuronal precursors and UVB-exposed skin cells [49, 50]. A key finding of our study, however, is the exacerbation of renal cell proliferation and apoptosis induced by caffeine in cystic kidneys.

Renal fibrosis was markedly and significantly higher in the CyCaf group than in all other groups. Higher renal fibrosis in cystic animals was indeed expected [16] as a result of a persistent inflammatory infiltrate observed in ADPKD human kidneys and rodent models, which is often associated with expanding cysts [51-53] and ultimately contributes to aggravate 
disease progression [54]. Epithelial changes appear to precede and drive interstitial changes in ADPKD kidneys, leading to the development of fibrosis in a biphasic way: alterations in cystic epithelia precipitate changes in interstitial fibroblasts, and reciprocal interactions between these cell types drive progressive accumulation of extracellular matrix [55]. Notably, our study revealed significant exacerbation in fibrosis in cystic kidneys of animals exposed to caffeine, likely because of acceleration of cyst expansion.

Although Pkd1 deficiency can also be associated with extra-renal phenotypes, no significant differences were detected in liver or heart weight among the analyzed groups. Our findings are in agreement with a previous study, which reported increased heart weight in cystic mice at the age of 24 but not at 13 weeks [37].

The high dose of caffeine employed in the present work ( $3 \mathrm{mg} / \mathrm{d})$, aiming to perform a "proof-of-principle" study relating caffeine to ADPKD progression, is not within the common range of human consumption. This scenario renders difficult comparisons with literature related to human disease [56]. The caffeine amount of $1 \mathrm{mg} / \mathrm{d}$ previously used by Tanner et al. in Han:SPRD rats [14] was equivalent to a human intake of approximately 4 cups of coffee/ day, whereas in other studies, mice were chronically exposed to 2-3 mg of caffeine per day [57-59]. Based on these reports, the dose we chose was not unreasonable. Our data indicate, however, that caffeine intake was responsible for low BW and apparently contributed to lower birth rates and higher mortality (data not shown).

The HALT-PKD study showed that ADPKD patients with relatively preserved renal function submitted to rigorous blood pressure (BP) control displayed a lower rate of total kidney volume (TKV) increase than the patients submitted to standard BP control $[6,60]$. Based on these data and on the fact that caffeine can potentially increase BP, it would be interesting to assess this parameter in our mice. Due to the significant mortality associated with invasive BP measurement, however, we decided not to perform this analysis. Despite the lack of these data, it should be noted that even if a caffeine-induced increase in BP was detected, it would be highly unlikely that it would be responsible for a major component of the caffeine-mediated increase in renal cystic index because the effect on TKV described in humans is relatively too small to explain the magnitude of the TKV increase observed in our caffeine-treated cystic mice. Moreover, in a previous study, caffeine exacerbated hypertension in the Han: SPRD cystic rat model but did not affect cyst development [14]. In addition, the HALT-PKD data were associated with BP reduction to levels below the average normal range [6], while in our animals, caffeine would likely increase BP. In this case, one should not only not assume an equivalent but opposite effect on TKV for symmetrical negative and positive $\mathrm{BP}$ variations but also consider that our cystic mouse model was previously shown to be hypertensive as early as at 5 weeks of age [16]. Therefore, even if a caffeine-associated BP increase was present, it would occur on the top of an already hypertensive animal, making potential predictions on TKV even harder.

Limited treatment options are available for ADPKD control, and identifying potential molecular targets for ADPKD remains an important goal. In the present study, cAMP and p-ERK were not shown to be involved in caffeine-induced cyst enlargement. However, as recently hypothesized, alterations in Hippo pathway signaling and the RhoA-YAP-c-Myc axis in Pkd1 mutant ADPKD may contribute to kidney cystogenesis [61]. Further experiments addressing the role of caffeine upon cystogenesis focusing on these and other pathways are still warranted.

\section{Conclusion}

In conclusion, our study is the first report to establish an association between caffeine intake and the progression of renal cystic disease in an in vivo model orthologous to human ADPKD. Caffeine effects on Pkd1-deficient cystic mice were demonstrated in a high-dose and long-term setting, starting at conception. Such effects included not only a significant increase in cyst growth and kidney volume but also increased renal cell proliferation, 


\section{Cellular Physiology Cell Physiol Biochem 2019;52:1061-1074 \\ \begin{tabular}{ll|l} 
and Biochemistry & $\begin{array}{l}\text { DOl: 10.33594/000000072 } \\
\text { Published online: } 13 \text { April } 2019\end{array}$ & $\begin{array}{l}\text { O } 2019 \text { The Author(s). Published by } \\
\text { Cell Physiol Biochem Press GmbH\&Co. KG }\end{array}$ \\
\cline { 2 - 3 } &
\end{tabular} \\ Meca et al.: Caffeine and Cystic Kidney Disease in Mice}

apoptosis and fibrosis. Having the proof of principle in hand, additional studies using lower doses of caffeine, equivalent to regular human consumption, and limiting caffeine exposure to different postnatal periods are important to perform. While we wait for the performance and conclusion of these studies, which will likely define more specifically such effects of caffeine, our findings support the recommendation of caffeine restriction in ADPKD patients. Moreover, because caffeine exposure included embryonic life through the administration of high doses of caffeine to noncystic mothers in our study, it may be reasonable to aware pregnant non-ADPKD women with at-risk fetuses to avoid caffeine during pregnancy.

\section{Acknowledgements}

We thank Marciana Veloso, Zenaide P. Moyses, Margoth R. Garnica and Olinda Ykuta for technical assistance.

This study was performed in accordance with international standards of animal care and experimentation, and the institutional ethics committee on animal use of the Federal University of Sao Paulo approved this study.

This study was supported by Fundação de Amparo à Pesquisa do Estado de São Paulo (FAPESP - Grant number 2011/21593-4) and Conselho Nacional de Desenvolvimento Científico e Tecnológico (CNPq - Grant numbers 142591/2011-4 (RM) and 309045/2018-5 (IPH). Portions of this study were presented at the American Society of Nephrology Annual Meeting - Kidney Week 2015, Nov 3-8, San Diego, CA, in USA.

R. Meca: conceptualization, methodology, validation, formal analysis, investigation, writing including original draft preparation, review and editing, supervision, and funding acquisition; B. E. Balbo: methodology, formal analysis, and investigation; M. S. Ormanji: methodology, validation, formal analysis, investigation, and writing including review and editing; J. M. Fonseca: formal analysis and investigation; L. R. Ianuzzi: methodology, investigation, and supervision; E. S. Costa: formal analysis and investigation; L. F. Onuchic: conceptualization, methodology, validation, writing including original draft preparation, review and editing, supervision, and funding acquisition; I. P. Heilberg: conceptualization, methodology, validation, writing including original draft preparation, review and editing, supervision, and funding acquisition.

\section{Disclosure Statement}

The authors have no conflicts of interest to declare.

\section{References}

1 Torres VE, Harris PC: Autosomal dominant polycystic kidney disease: the last 3 years. Kidney Int 2009;76:149-168.

2 Grantham JJ, Mulamalla S, Swenson-Fields KI: Why kidneys fail in autosomal dominant polycystic kidney disease. Nat Rev Nephrol 2011;7:556-566.

3 Harris PC, Torres VE: Genetic mechanisms and signaling pathways in autosomal dominant polycystic kidney disease. J Clin Invest 2014;124:2315-2324.

4 Belibi FA, Reif G, Wallace DP, Yamaguchi T, Olsen L, Li H, Helmkamp GM, Grantham JJ: Cyclic AMP promotes growth and secretion in human polycystic kidney epithelial cells. Kidney Int 2004;66:964-973.

5 Bastos AP, Onuchic LF: Molecular and cellular pathogenesis of autosomal dominant polycystic kidney disease. Braz J Med Biol Res 2011;44:606-617.

6 Schrier RW, Brosnahan G, Cadnapaphornchai MA, Chonchol M, Friend K, Gitomer B, Rossetti S: Predictors of autosomal dominant polycystic kidney disease progression. J Am Soc Nephrol 2014;25:2399-2418. 


\section{Cellular Physiology Cell Physiol Biochem 2019;52:1061-1074

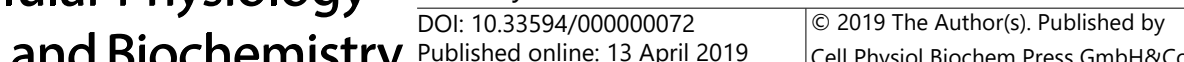 and Biochemistry Published online: 13 April 2019 Cell Physiol Biochem Press GmbH\&Co. KG \\ Meca et al.: Caffeine and Cystic Kidney Disease in Mice}

- 7 Grantham JJ, Chapman AB, Torres VE: Volume progression in autosomal dominant polycystic kidney disease: the major factor determining clinical outcomes. Clin J Am Soc Nephrol 2006;1:148-157.

8 Grantham JJ: Clinical practice. Autosomal dominant polycystic kidney disease. N Engl J Med 2008;359:1477-1485.

9 Irazabal MV, Rangel LJ, Bergstralh EJ, Osborn SL, Harmon AJ, Sundsbak JL, Bae KT, Chapman AB, Grantham JJ, Mrug M, Hogan MC, El-Zoghby ZM, Harris PC, Erickson BJ, King BF, Torres VE: Imaging classification of autosomal dominant polycystic kidney disease: a simple model for selecting patients for clinical trials. J Am Soc Nephrol 2015;26:160-172.

10 Torres VE, Grantham JJ, Chapman AB, Mrug M, Bae KT, King BF, Jr., Wetzel LH, Martin D, Lockhart ME, Bennett WM, Moxey-Mims M, Abebe KZ, Lin Y, Bost JE: Potentially modifiable factors affecting the progression of autosomal dominant polycystic kidney disease. Clin J Am Soc Nephrol 2011;6:640-647.

11 Torres VE, Bankir L, Grantham JJ: A case for water in the treatment of polycystic kidney disease. Clin J Am Soc Nephrol 2009;4:1140-1150.

12 Taylor JM, Hamilton-Reeves JM, Sullivan DK, Gibson CA, Creed C, Carlson SE, Wesson DE, Grantham JJ: Diet and polycystic kidney disease: A pilot intervention study. Clin Nutr 2016;36:458-466.

13 Vendramini LC, Nishiura JL, Baxmann AC, Heilberg IP: Caffeine intake by patients with autosomal dominant polycystic kidney disease. Braz J Med Biol Res 2012;45:834-840.

14 Tanner GA, Tanner JA: Chronic caffeine consumption exacerbates hypertension in rats with polycystic kidney disease. Am J Kidney Dis 2001;38:1089-1095.

- 15 Nishiura JL, Neves RF, Eloi SR, Cintra SM, Ajzen SA, Heilberg IP: Evaluation of nephrolithiasis in autosomal dominant polycystic kidney disease patients. Clin J Am Soc Nephrol 2009;4:838-844.

16 Fonseca JM, Bastos AP, Amaral AG, Sousa MF, Souza LE, Malheiros DM, Piontek K, Irigoyen MC, Watnick TJ, Onuchic LF: Renal cyst growth is the main determinant for hypertension and concentrating deficit in Pkd1deficient mice. Kidney Int 2014;85:1137-1150.

17 Hanaoka K, Guggino WB: cAMP regulates cell proliferation and cyst formation in autosomal polycystic kidney disease cells. J Am Soc Nephrol 2000;11:1179-1187.

18 Belibi FA, Wallace DP, Yamaguchi T, Christensen M, Reif G, Grantham JJ: The effect of caffeine on renal epithelial cells from patients with autosomal dominant polycystic kidney disease. J Am Soc Nephrol 2002;13:2723-2729.

19 Torres VE, Wang X, Qian Q, Somlo S, Harris PC, Gattone VH: Effective treatment of an orthologous model of autosomal dominant polycystic kidney disease. Nat Med 2004;10:363-364.

20 Wang X, Gattone V, 2nd, Harris PC, Torres VE: Effectiveness of vasopressin V2 receptor antagonists OPC-31260 and OPC-41061 on polycystic kidney disease development in the PCK rat. J Am Soc Nephrol 2005;16:846-851.

- 21 Gattone VH, 2nd, Wang X, Harris PC, Torres VE: Inhibition of renal cystic disease development and progression by a vasopressin V2 receptor antagonist. Nat Med 2003;9:1323-1326.

22 Torres VE, Higashihara E, Devuyst O, Chapman AB, Gansevoort RT, Grantham JJ, Perrone RD, Ouyang J, Blais JD, Czerwiec FS: Effect of Tolvaptan in Autosomal Dominant Polycystic Kidney Disease by CKD Stage: Results from the TEMPO 3:4 Trial. Clin J Am Soc Nephrol 2016;11:803-811.

23 Wang X, Wu Y, Ward CJ, Harris PC, Torres VE: Vasopressin Directly Regulates Cyst Growth in Polycystic Kidney Disease. J Am Soc Nephrol 2008;19:102-108.

24 Girardat-Rotar L, Puhan MA, Braun J, Serra AL: Long-term effect of coffee consumption on autosomal dominant polycystic kidneys disease progression: results from the Suisse ADPKD, a Prospective Longitudinal Cohort Study. J Nephrol 2018;31:87-94.

25 Greenwood DC, Thatcher NJ, Ye J, Garrard L, Keogh G, King LG, Cade JE: Caffeine intake during pregnancy and adverse birth outcomes: a systematic review and dose-response metaanalysis. Eur J Epidemiol 2014;29:725-734.

26 Serapiao-Moraes DF, Souza-Mello V, Aguila MB, Mandarim-de-Lacerda CA, Faria TS: Maternal caffeine administration leads to adverse effects on adult mice offspring. Eur J Nutr 2013;52:1891-1900.

27 Chen J, Boyle S, Zhao M, Su W, Takahashi K, Davis L, Decaestecker M, Takahashi T, Breyer MD, Hao CM: Differential expression of the intermediate filament protein nestin during renal development and its localization in adult podocytes. J Am Soc Nephrol 2006;17:1283-1291.

- 28 Woon C, Bielinski-Bradbury A, O’Reilly K, Robinson P: A systematic review of the predictors of disease progression in patients with autosomal dominant polycystic kidney disease. BMC Nephrol 2015;16:140. 


\section{Cellular Physiology Cell Physiol Biochem 2019;52:1061-1074

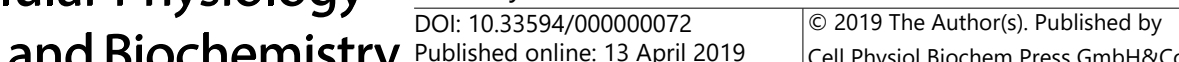 and Biochemistry Published online: 13 April 2019 Cell Physiol Biochem Press GmbH\&Co. KG \\ Meca et al.: Caffeine and Cystic Kidney Disease in Mice}

- 29 Alam A, Dahl NK, Lipschutz JH, Rossetti S, Smith P, Sapir D, Weinstein J, McFarlane P, Bichet DG: Total Kidney Volume in Autosomal Dominant Polycystic Kidney Disease: A Biomarker of Disease Progression and Therapeutic Efficacy. Am J Kidney Dis 2015;66:564-576.

- 30 Yamaguchi T, Nagao S, Kasahara M, Takahashi H, Grantham JJ: Renal accumulation and excretion of cyclic adenosine monophosphate in a murine model of slowly progressive polycystic kidney disease. Am J Kidney Dis 1997;30:703-709.

31 Ye H, Wang X, Sussman CR, Hopp K, Irazabal MV, Bakeberg JL, LaRiviere WB, Manganiello VC, Vorhees CV, Zhao H, Harris PC, van Deursen J, Ward CJ, Torres VE: Modulation of Polycystic Kidney Disease Severity by Phosphodiesterase 1 and 3 Subfamilies. J Am Soc Nephrol 2016;27:1312-1320.

32 Yamashita Y, Akaike N: Caffeine-induced chloride current in dissociated rat hepatocytes. Am J Physiol 1996;270:C508-513.

33 Miwa S, Sugimoto N, Yamamoto N, Shirai T, Nishida H, Hayashi K, Kimura H, Takeuchi A, Igarashi K, Yachie A, Tsuchiya H: Caffeine induces apoptosis of osteosarcoma cells by inhibiting AKT/mTOR/S6K, NF-kappaB and MAPK pathways. Anticancer Res 2012;32:3643-3649.

34 Wang H, Guan W, Yang W, Wang Q Zhao H, Yang F, Lv X, Li J: Caffeine inhibits the activation of hepatic stellate cells induced by acetaldehyde via adenosine A2A receptor mediated by the cAMP/PKA/SRC/ ERK1/2/P38 MAPK signal pathway. PLoS One 2014;9:e92482.

35 Takakura A, Contrino L, Zhou X, Bonventre JV, Sun Y, Humphreys BD, Zhou J: Renal injury is a third hit promoting rapid development of adult polycystic kidney disease. Hum Mol Genet 2009;18:2523-2531.

- 36 Weimbs T: Third-Hit Signaling in Renal Cyst Formation. J Am Soc Nephrol 2011;22:793-795.

- 37 Bastos AP, Piontek K, Silva AM, Martini D, Menezes LF, Fonseca JM, Fonseca II, Germino GG, Onuchic LF: Pkd1 haploinsufficiency increases renal damage and induces microcyst formation following ischemia/ reperfusion. J Am Soc Nephrol 2009;20:2389-2402.

38 Leuenroth SJ, Bencivenga N, Igarashi P, Somlo S, Crews CM: Triptolide reduces cystogenesis in a model of ADPKD. J Am Soc Nephrol 2008;19:1659-1662.

39 Shillingford JM, Murcia NS, Larson CH, Low SH, Hedgepeth R, Brown N, Flask CA, Novick AC, Goldfarb DA, Kramer-Zucker A, Walz G, Piontek KB, Germino GG, Weimbs T: The mTOR pathway is regulated by polycystin-1, and its inhibition reverses renal cystogenesis in polycystic kidney disease. Proc Natl Acad Sci U S A 2006;103:5466-5471.

40 Raphael KL, Strait KA, Stricklett PK, Baird BC, Piontek K, Germino GG, Kohan DE: Effect of pioglitazone on survival and renal function in a mouse model of polycystic kidney disease. Am J Nephrol 2009;30:468-473.

- 41 Ming Z, Lautt WW: Caffeine-induced natriuresis and diuresis via blockade of hepatic adenosine-mediated sensory nerves and a hepatorenal reflex. Can J Physiol Pharmacol 2010;88:1115-1121.

42 Shirley DG, Walter SJ, Noormohamed FH: Natriuretic effect of caffeine: assessment of segmental sodium reabsorption in humans. Clin Sci (Lond) 2002;103:461-466.

43 Welch WJ: Adenosine, type 1 receptors: role in proximal tubule Na+ reabsorption. Acta Physiol (Oxf) 2015;213:242-248.

44 Gabow PA, Chapman AB, Johnson AM, Tangel DJ, Duley IT, Kaehny WD, Manco-Johnson M, Schrier RW: Renal structure and hypertension in autosomal dominant polycystic kidney disease. Kidney Int 1990;38:1177-1180.

45 Seeman T, Dusek J, Vondrak K, Blahova K, Simkova E, Kreisinger J, Dvorak P, Kyncl M, Hribal Z, Janda J: Renal concentrating capacity is linked to blood pressure in children with autosomal dominant polycystic kidney disease. Physiol Res 2004;53:629-634.

46 Ramasubbu K, Gretz N, Bachmann S: Increased epithelial cell proliferation and abnormal extracellular matrix in rat polycystic kidney disease. J Am Soc Nephrol 1998;9:937-945.

47 Schafer K, Gretz N, Bader M, Oberbaumer I, Eckardt KU, Kriz W, Bachmann S: Characterization of the Han: SPRD rat model for hereditary polycystic kidney disease. Kidney Int 1994;46:134-152.

48 Trudel M, Barisoni L, Lanoix J, D’Agati V: Polycystic kidney disease in SBM transgenic mice: role of c-myc in disease induction and progression. Am J Pathol 1998;152:219-229.

49 Wentz CT, Magavi SS: Caffeine alters proliferation of neuronal precursors in the adult hippocampus. Neuropharmacology 2009;56:994-1000.

50 Han ME, Park KH, Baek SY, Kim BS, Kim JB, Kim HJ, Oh SO: Inhibitory effects of caffeine on hippocampal neurogenesis and function. Biochem Biophys Res Commun 2007;356:976-980.

51 Vernon MA, Mylonas KJ, Hughes J: Macrophages and renal fibrosis. Semin Nephrol 2010;30:302-317. 


\section{Cellular Physiology Cell Physiol Biochem 2019;52:1061-1074

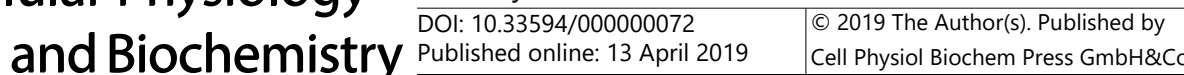 \\ Meca et al.: Caffeine and Cystic Kidney Disease in Mice}

- 52 Wynn TA, Barron L: Macrophages: master regulators of inflammation and fibrosis. Semin Liver Dis 2010;30:245-257.

53 Karihaloo A, Koraishy F, Huen SC, Lee Y, Merrick D, Caplan MJ, Somlo S, Cantley LG: Macrophages promote cyst growth in polycystic kidney disease. J Am Soc Nephrol 2011;22:18091814.

- 54 Okada H, Ban S, Nagao S, Takahashi H, Suzuki H, Neilson EG: Progressive renal fibrosis in murine polycystic kidney disease: an immunohistochemical observation. Kidney Int 2000;58:587597.

55 Norman J: Fibrosis and progression of autosomal dominant polycystic kidney disease (ADPKD). Biochim Biophys Acta 2011;1812:1327-1336.

56 Brent RL, Christian MS, Diener RM: Evaluation of the reproductive and developmental risks of caffeine. Birth Defects Res B Dev Reprod Toxicol 2011;92:152-187.

57 Cao C, Cirrito JR, Lin X, Wang L, Verges DK, Dickson A, Mamcarz M, Zhang C, Mori T, Arendash GW, Holtzman DM, Potter H: Caffeine suppresses amyloid-beta levels in plasma and brain of Alzheimer's disease transgenic mice. J Alzheimers Dis 2009;17:681-697.

58 Kaster MP, Machado NJ, Silva HB, Nunes A, Ardais AP, Santana M, Baqi Y, Muller CE, Rodrigues AL, Porciuncula LO, Chen JF, Tome AR, Agostinho P, Canas PM, Cunha RA: Caffeine acts through neuronal adenosine A2A receptors to prevent mood and memory dysfunction triggered by chronic stress. Proc Natl Acad Sci U S A 2015;112:7833-7838.

- 59 Onaolapo OJ, Onaolapo AY, Akanmu MA, Olayiwola G: Caffeine/sleep-deprivation interaction in mice produces complex memory effects. Ann Neurosci 2015;22:139-149.

60 Schrier RW, Abebe KZ, Perrone RD, Torres VE, Braun WE, Steinman TI, Winklhofer FT, Brosnahan G, Czarnecki PG, Hogan MC, Miskulin DC, Rahbari-Oskoui FF, Grantham JJ, Harris PC, Flessner MF, Bae KT, Moore CG, Chapman AB: Blood Pressure in Early Autosomal Dominant Polycystic Kidney Disease. N Engl J Med 2014;371:2255-2266.

61 Cai J, Song X, Wang W, Watnick T, Pei Y, Qian F, Pan D: A RhoA-YAP-c-Myc signaling axis promotes the development of polycystic kidney disease. Genes Dev 2018;32:781-793. 